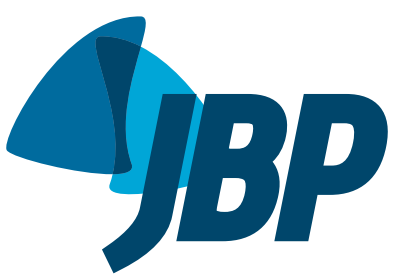

\section{Bronchial thermoplasty in a patient with difficult-to-control asthma}

\author{
Adalberto Rubin ${ }^{1,2}$, Suzana Zelmanovitz ${ }^{1}$, Manuela Cavalcanti', \\ Fernanda Spilimbergo ${ }^{1}$, Paulo Goldenfum ${ }^{1}$, José Felicetti ${ }^{3}$, Paulo Cardoso ${ }^{4}$
}

\section{TO THE EDITOR:}

A small but significant proportion of asthma patients have persistent symptoms, lung function changes, and frequent exacerbations, despite appropriate management. ${ }^{(1,2)}$ This subset of patients, who are classified as having difficult-to-control asthma (DTCA), have high morbidity and mortality rates, as well as consuming a large part of the health resources allocated to the disease. Bronchial thermoplasty $(B T)^{(3)}$ is the first nonpharmacological treatment for patients with DTCA and is currently available in several countries, including Brazil.

A 46-year-old female patient with DTCA receiving continuous treatment with salmeterol/fluticasone (50/500 $\mu \mathrm{g}$ twice daily) and omalizumab (200 mg every two weeks) for the past 2 years presented to our facility. Despite the aforementioned treatment, she had had three episodes of exacerbation in the previous year and was unable to tolerate physical activity, often using inhaled albuterol for symptom relief. Although she had preserved lung function, her $\mathrm{FEV}_{1}$ being $2.5 \mathrm{~L}$ ( $85 \%$ of predicted), she had poorly controlled asthma. In June of 2014, her Asthma Control Test (ACT) score was 10. Patients with an ACT score of less than 20 are considered to have uncontrolled asthma. On August 19, 2014, the patient underwent BT for the first time, the right lower lobe being treated (Figure 1). She underwent another two BT procedures, three weeks apart, the left lower lobe and upper lobes being treated. A total of 152 activations were performed. All procedures were performed with the patient under general anesthesia. There were no significant complications, and the patient was discharged $4 \mathrm{~h}$ after each procedure. Clinical and functional evaluation performed at 60 days after the last procedure revealed stable lung function, her $\mathrm{FEV}_{1}$ being $2.58 \mathrm{~L}(88 \%$ of predicted), and significantly improved disease control, her ACT score being 23 (Table 1). In addition to increased exercise tolerance, the patient reported virtually no rescue albuterol use.

The objective of BT is to reduce the thickness of segmental and subsegmental bronchial smooth muscle through the delivery of radiofrequency energy to the airways. $^{(3)}$ The resulting anatomical change is intended to provide clinical benefits to asthma patients, reducing airway smooth muscle contractility and possibly reducing bronchoconstriction and asthma exacerbation.

Preliminary studies of BT use showed improved morning and evening PEF, as well as reduced rescue bronchodilator use, ${ }^{(4)}$ together with improved quality of life. The first multicenter study of BT use ${ }^{(3)}$ showed better disease control in asthma patients treated with BT than in controls. In a subsequent study involving patients with severe asthma, the aforementioned results were confirmed. ${ }^{(5)}$ The aforementioned studies provided the basis for the largest study to date, ${ }^{(6)}$ in which nearly 300 asthma patients were randomized to receive BT + conventional treatment or conventional treatment alone (the latter constituting the control group). The study was a double-blind trial and showed that the asthma patients who were treated with BT had a significant reduction in severe exacerbations and emergency room visits for asthma. On the basis of the aforementioned results, the US Food and Drug Administration approved the clinical use of BT in 2010. A 5-year follow-up evaluation showed a maintained reduction in exacerbations and emergency room visits, no BT-related adverse effects or anatomical abnormalities being observed. ${ }^{(7)}$

In the case reported here, treatment with BT was effective (as evidenced by the ACT score) and well tolerated, results that are consistent with those of previous studies. ${ }^{(5)}$ Similar results have been reported in Brazil. ${ }^{(8)}$ BT is a new treatment modality that is aimed at patients with severe asthma in whom the disease remains uncontrolled despite the use of all available drugs, including omalizumab.

In Brazil, this is the first case report of a patient treated with BT after the use of BT was approved by national

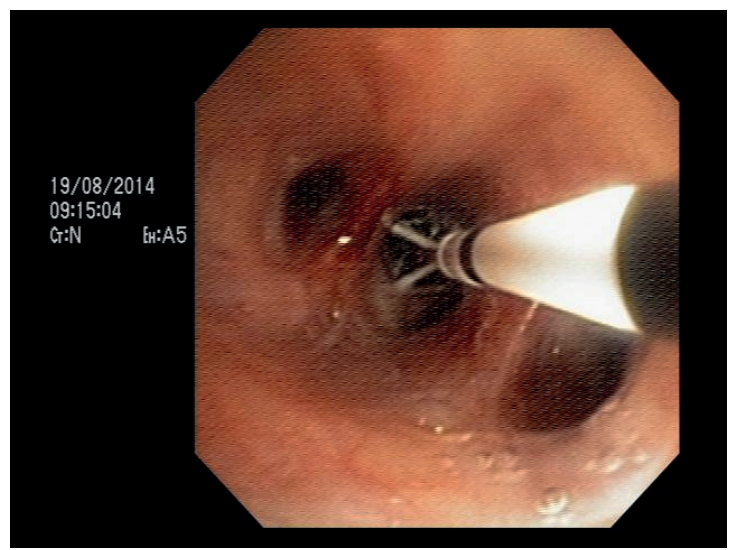

Figure 1. Photograph showing the use of bronchial thermoplasty. 
Table 1. Clinical and functional evaluation performed at baseline and after treatment with bronchial thermoplasty.

\begin{tabular}{lcc}
\multicolumn{1}{c}{ Variable } & Baseline & After treatment \\
FVC, L & 3.53 & 3.57 \\
FVC, \% of predicted & 97.9 & 99.1 \\
FEV $_{1}$, L & 2.5 & 2.58 \\
FEV $_{1}, \%$ of predicted & 85.0 & 88.0 \\
ACT score & 10 & 23 \\
\hline
\end{tabular}

ACT: Asthma Control Test. regulatory agencies. The results of previous studies and those of the present study show that BT is a promising treatment option for the management of moderate to severe asthma. BT has been approved for clinical use in several countries and has recently been included in the Global Initiative for Asthma guidelines as a treatment option for patients with severe asthma. ${ }^{(1)}$ In the near future, BT is expected to become a treatment option for DTCA patients nationwide.

\section{REFERENCES}

1. Global Initiative for Asthma - GINA [homepage on the Internet] Bethesda: GINA [updated 2014; cited 2015 Jan 21]. Global Strategy for Asthma Management and Prevention. Available from : http:// www.ginasthma.org/

2. Wenzel SE. Severe asthma in adults. Am J Respir Crit Care Med. 2005;172(2):149-60. http://dx.doi.org/10.1164/rccm.200409-1181PP

3. Cox G, Miller JD, McWilliams A, Fitzgerald JM, Lam S. Bronchial thermoplasty for asthma. Am J Respir Crit Care Med. 2006;173(9):965-9. http://dx.doi.org/10.1164/rccm.200507-11620C

4. Cox G, Thomson NC, Rubin AS, Niven RM, Corris PA, Siersted HC, et al. Asthma control during the year after bronchial thermoplasty. New Engl J Med. 2007;356(13):1327-37. http://dx.doi.org/10.1056/ NEJMoa064707

5. Pavord ID, Cox G, Thomson NC, Rubin AS, Corris PA, Niven RM, et al. Safety and efficacy of bronchial thermoplasty in symptomatic,

severe asthma. Am J Respir Crit Care Med. 2007;176(12):1185-91. http://dx.doi.org/10.1164/rccm.200704-5710C

6. Castro M, Rubin AS, Laviolette M, Fiterman J, De Andrade Lima M, Shah $\mathrm{PL}$, et al. Effectiveness and safety of bronchial thermoplasty in the treatment of severe asthma: a multicenter, randomized, doubleblind, sham-controlled clinical trial. Am J Respir Crit Care Med. 2010;181(2):116-24. http://dx.doi.org/10.1164/rccm.200903-03540C

7. Wechsler ME, Laviolette M, Rubin AS, Fiterman J, Lapa e Silva $J R$, Shah PL, et al. Bronchial thermoplasty: Long-term safety and effectiveness in patients with severe persistent asthma. J Allergy Clin Immunol. 2013;132(6):1295-302. http://dx.doi.org/10.1016/j. jaci.2013.08.009

8. Rubin AS, Cardoso PF. Bronchial thermoplasty: report on the first endoscopic treatment for asthma in Latin America. J Bras Pneumol. 2008;34(1):59-62. http://dx.doi.org/10.1590/S180637132008000100011 